Int. J. Electrochem. Sci., 12 (2017) $5792-5803$

International Journal of

ELECTROCHEMICAL

SCIENCE

www.electrochemsci.org

\title{
Cobalt Hydroxide Nanoflakes Prepared by Saccharide-Assisted Cathodic Electrochemical Deposition as High Performance Supercapacitor Electrode Material
}

\author{
Mustafa Aghazadeh ${ }^{1}$, Mohammad Reza Ganjali, ${ }^{2,3}$ and Mohammad Ghannadi Maragheh $^{1}$ \\ ${ }^{1}$ Material and Nuclear Research School, Nuclear Science and Technology Research Institute (NSTRI), \\ P.O. Box 14395-834, Tehran, Iran \\ ${ }^{2}$ Center of Excellence in Electrochemistry, School of Chemistry, University of Tehran, Tehran, Iran \\ ${ }^{3}$ Biosensor Research Center, Endocrinology and Metabolism Molecular-Cellular Sciences Institute, \\ Tehran University of Medical Sciences, Tehran, Iran \\ *E-mail: ganjali@khayam.ut.ac.ir
}

doi: $10.20964 / 2017.06 .48$

Received: 4 March 2017 / Accepted: 16 April 2017 / Published: 12 May 2017

Cobalt hydroxide flake-like nanostructures are prepared through green electrochemical synthesis procedure. In this way, an aqueous solution of $0.005 \mathrm{M}$ cobalt chloride and $1 \mathrm{~g} / \mathrm{L}$ starch was used as an electrosynthesis bath. The cobalt hydroxide deposit was prepared in a two-electrode system containing stain less steel cathode and graphite anode by applying current density of $10 \mathrm{~mA} \mathrm{~cm}$. The structural characterization by XRD, IR, FE-SEM and TEM confirmed that the deposited sample is composed of $\beta$-cobalt hydroxide with flake-like morphology. The charge storage ability of the prepared nanoflakes was further evaluated using cyclic voltammetry (CV), galvanostat charge-discharge (GCD) cycling and electrochemical impedance spectroscopy (EIS). The electrochemical measurement revealed that the prepared cobalt hydroxide has low equivalent series resistance $\left(\mathrm{R}_{\mathrm{s}}\right)$ and charge transfer resistance $\left(\mathrm{R}_{\mathrm{ct}}\right)$, which enabled the fabricated electrode to deliver specific capacitances as high as 1125.4, 992, 849.3, 701.6 and $452.5 \mathrm{~F} \mathrm{~g}^{-1}$ at $1,2,3,5$ and $10 \mathrm{~A} \mathrm{~g}^{-1}$, respectively, and capacity retentions $93.48 \%$ and $80.17 \%$ after $2000 \mathrm{GCD}$ at the current loads of 1 and $5 \mathrm{~A} \mathrm{~g}^{-1}$. These results supported the proper characteristics of the prepared nanomaterials for the supercapacitor applications.

Keywords: Cobalt hydroxide; Flake structures; Green Electrosynthesis; Supercapacitive performance

\section{FULL TEXT}

(C) 2017 The Authors. Published by ESG (www.electrochemsci.org). This article is an open access article distributed under the terms and conditions of the Creative Commons Attribution license (http://creativecommons.org/licenses/by/4.0/). 